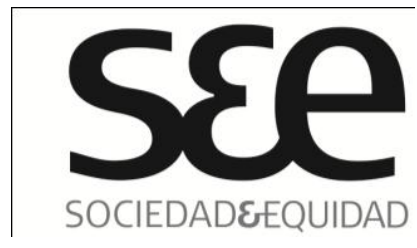

\section{Aproximación a la medición de la pobreza infantil desde un enfoque multidimensional y de derechos}

A Multidimensional and rights approach to the measurement of Child Poverty

\title{
Resumen
}

Desde una perspectiva crítica del enfoque monetario de medición de la pobreza, el artículo revisa las recientes propuestas de medición multidimensional de la pobreza y en particular la realizada por CEPAL y UNICEF. Las preguntas guías fueron: ¿Qué indicadores se deben considerar y qué situaciones deberían ser definidas como deficitarias? ¿Cuáles son los umbrales mínimos que deben ser garantizados? ¿Cuáles son las medidas estandarizadas que permitirían una efectiva evaluación de los avances logrados en la lucha contra la pobreza en la niñez y adolescencia en Argentina? Se

\footnotetext{
${ }^{1}$ Doctora en Ciencias Sociales (UBA). Coordinadora del Proyecto de investigación "Barómetro de la Deuda Social de la Infancia" del Programa del Observatorio de la Deuda Social Argentina (UCA). Investigadora responsable del Proyecto de Investigación Científico y Tecnológico PICT 2010-2195 del Fondo para la Investigación Científica y Tecnológica (FONCYT). Especialista en desarrollo humano y social de la Infancia.

${ }^{2}$ Licenciada en Economía (UCA). Becaria de investigación de la Universidad Católica Argentina en el marco del Proyecto "Barómetro de la Deuda Social de la Infancia" del Programa del Observatorio de la Deuda Social Argentina. Temática de investigación: condiciones de vida y desarrollo de la niñez y adolescencia.
} 


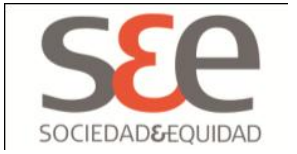

desarrolló una propuesta que define dimensiones de derechos y umbrales en una "línea de corte dual", permitiendo así diferenciar entre pobreza severa y moderada. Se reconocieron y describieron los principales factores sociodemográficos asociados de modo estructural y permanente a la pobreza infantil. El estudio reveló que, para el 2011, el 26,6\% de los niños/as y adolescentes de Argentina urbana pertenecía a hogares con carencias sociales en dimensiones de derechos $(13,7 \%$ con privaciones moderadas y $12,9 \%$ con severas). Las carencias sociales en el espacio del hábitat representaban el $61,4 \%$ de la pobreza severa. Estas estimaciones se realizaron a partir de los microdatos de la Encuesta de la Deuda Social Argentina (EDSA) del Programa del Observatorio de la Deuda Social Argentina de la Universidad Católica Argentina (UCA).

\section{Palabras Claves}

Pobreza multidimensional, Enfoque de derechos, Desarrollo humano y social, Infancia, Argentina urbana.

\section{Abstract}

From a critical perspective towards the monetary approaches to poverty measurement, this paper seeks to continue the review of the recent proposals of multidimensional measurement of poverty, especially the one carried out by ECLAC and UNICEF. In this framework, we wonder: What indicators should be taken into account and what situations should be considered as deficit? What minimum thresholds should be guaranteed? What standardized measures would allow for an effective evaluation of the progress made in fighting child poverty in Argentina? This paper presents a proposal that defines rights dimensions and thresholds in a "dual cutoff", differentiating between severe and moderate poverty. Moreover, we recognize and describe the main socio-demographic factors associated in a more structural and permanent way to child poverty. In $2011,26,6 \%$ of children and adolescents belonged to households with social shortage in rights dimensions $(13,7 \%$ had moderate shortage and $12,9 \%$ had severe ones). Deficit in living conditions represented $61,4 \%$ of severe poverty. The estimates were drawn from micro-data from the "Argentinean Survey of Social Debt" (EDSA) from the Observatory Programme of Social Debt of Argentina (2011), from the Catholic University of Argentina (UCA).

\section{Keywords}

Multidimensional poverty, Rights based approach, Human and social development, Childhood, Urban Argentina. 


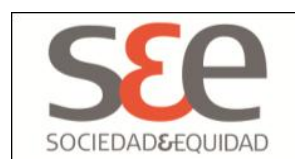

\section{Introducción}

La niñez y la adolescencia son poblaciones especialmente vulnerables a la experiencia de la pobreza. La situación de pobreza expone a la niñez y adolescencia a múltiples riesgos. Una alimentación deficitaria, un medio ambiente insalubre, o la falta de estímulos emocionales e intelectuales en los primeros años de vida, comprometen el desarrollo cognitivo del niño/a, y condicionan el ejercicio de otros tantos derechos humanos y sociales básicos para el desarrollo de su máximo potencial. Del mismo modo, experimentar la pobreza en la adolescencia suele exponer a los jóvenes a la explotación económica y/o doméstica. Esto favorece la deserción escolar de los mismos, la propensión a enfermedades y accidentes, entre otros riesgos sociales.

En efecto, las huellas que deja la pobreza en la niñez y adolescencia son difíciles de revertir en la adultez y comprometen el futuro de las sociedades. Sin embargo, poco se conoce sobre su magnitud, incidencia y composición.

En Argentina las mediciones oficiales de la pobreza se han basado principalmente en el método indirecto de línea de pobreza por ingresos y las estimaciones se suelen realizar a nivel de la población en general ${ }^{3}$.

Son conocidas las críticas a los enfoques monetaristas de medición de la pobreza basada en el ingreso de los hogares como aproximación al bienestar (CDESC, 2001; ONU, 2004), particularmente en lo que respecta a la medición de pobreza la infantil (DWP, 2003). Sin dudas, uno de los principales desarrollos conceptuales alternativos lo ha realizado Sen (1976), desde un enfoque de las capacidades y las necesidades del desarrollo humano. Los aportes orientados a captar el déficit en las condiciones de vida en dimensiones constitutivas del bienestar y la dignidad de las personas han sido múltiples (Alkire, 2002; MaxNeef, 1987; Nussbaum y Glover, 1995; Doyal y Gough, 1994, Boltvinik, 2003), y de modo creciente se han constituido en un marco de interpretación alternativo para la comprensión de los problemas de la pobreza y la equidad, que entendemos, guardan una estrecha relación conceptual con los derechos humanos.

Adhiriendo a estos enfoques, distintos organismos nacionales e internacionales han realizado propuestas de medición de la pobreza que reconocen el carácter multidimensional de la misma. En particular, cabe señalar los avances realizados en México por la CONEVAL (2010), y la reciente propuesta de medición de la pobreza infantil de CEPAL y UNICEF (2012).

\footnotetext{
${ }^{3}$ Cabe señalar que la estimación de la pobreza infantil no es el único desafío que enfrenta el sistema estadístico de la Argentina. Desde el año 2007 el Instituto Nacional de Estadísticas y Censos (INDEC) se encuentra intervenido por la Secretaría de Comercio Interior del Ministerio de Economía de la Nación. Dicha intervención produjo modificaciones en la metodología de medición de la pobreza e indigencia y una manipulación de los índices de precios (CELS, 2009).
} 


\section{SEe}

Convencidos de la importancia que reviste continuar la revisión de los métodos de medición de la pobreza infantil, así como la de los criterios conceptuales y procedimientos metodológicos utilizados para ello, es que realizaremos un ejercicio de revisión y adaptación de la metodología desarrollada recientemente por CEPAL y UNICEF. Para esto nos basamos en la normativa vigente en Argentina. Consideramos relevante replicar y expandir en la región estos estudios para contribuir a una mejor definición de las áreas de necesidades de la niñez y adolescencia en situación de pobreza.

Abordaremos dicha problemática a partir de las siguientes interrogantes: ¿Qué indicadores se deben considerar y qué situaciones deberían ser definidas como deficitarias? ¿Cuáles son los umbrales mínimos que deben ser garantizados? Y ¿Cuáles son las medidas estandarizadas que permitirían su comparación internacional y una efectiva evaluación de los avances logrados en la lucha contra la pobreza en la niñez y adolescencia?

Las estimaciones de incidencia que se presentan y analizan se basan en definiciones que toman como marco normativo principal la Convención de los Derechos del Niño (ONU, 1989). Las estimaciones fueron realizadas a partir de los microdatos de la Encuesta de la Deuda Social Argentina (EDSA), del Programa del Observatorio de la Deuda Social Argentina, (UCA), para el cuarto trimestre del $2011^{4}$.

\section{Antecedentes}

Se reconocen numerosos esfuerzos orientados a definir la pobreza infantil (Minujín, Delamónica y Davidziuk, 2006). Para nuestro estudio nos centraremos particularmente en los aportes realizados por CEPAL y UNICEF (2012). De esta última propuesta se valora el enfoque de derechos y la naturaleza multidimensional de la pobreza. La definición de la pobreza desde un enfoque de derechos parece especialmente importante en tanto su garantía puede ser legítimamente exigida a los Estados (PNUD, 2000; O'Donnell, 2002). Asimismo, las medidas multidimensionales permiten definir de modo más integral el

\footnotetext{
${ }^{4}$ La Encuesta de la Deuda Social Argentina (EDSA) es una encuesta de hogares multipropósito, que desde el 2004 releva datos de hogares y personas en grandes centros urbanos de la Argentina. La estructura de la encuesta se mantuvo a lo largo de los años con el objetivo de hacer comparaciones en el tiempo. En esta oportunidad se realizan estimaciones y análisis con la medición correspondiente al cuarto trimestre del 2011. La EDSA es representativa de población urbana de ciudades de 50.000 habitantes y más. La muestra considera las ciudades de Buenos Aires, Conurbano Bonaerense (24 partidos), Gran Córdoba, Gran Rosario, Gran Mendoza y San Rafael, Gran Salta, Gran Tucumán y Tafi Viejo, Mar del Plata, Gran Paraná, Gran San Juan, Gran Resistencia, Neuquén - Plottier, Zárate, Goya, La Rioja, Comodoro Rivadavia, Ushuaia y Río Grande. El diseño muestral considera 950 puntos, alcanza a 5700 hogares de los cuales 2076 tenían niños/as y adolescentes menores de 18 años y reunían 5598 niños/as y adolescentes.
} 


\section{SEe}

desarrollo humano de la infancia. En este sentido, la calidad de vida en la niñez y adolescencia debiera poder ser medida en aspectos materiales, emocionales y sociales.

Las medidas multidimensionales para la estimación de la pobreza se pueden definir en dos momentos (Sen, 1976): el de identificación y el de agregación. El primero establece los criterios que serán utilizados para definir si una persona es o no pobre, permitiendo identificar el número de privaciones que se requiere para encontrarse en situación de pobreza; mientras que el segundo momento establece el método en que se agregarán las privaciones a los efectos de generar una medida de pobreza de una población determinada.

Para la construcción de las mediciones de pobreza infantil se definió en una primera etapa el espacio de los derechos sociales, estableciendo un vínculo entre el ejercicio de los derechos y la medición de la pobreza, tomando como marco normativo principal la Convención de los Derechos del Niño (ONU, 1989), ratificada en la Argentina en el año 1990 e incorporada a la Constitución Nacional en la reforma de $1994^{5}$. En este sentido, los indicadores de privaciones sociales que se utilizaron para medir la pobreza cumplen con el requisito de permitir identificar elementos esenciales del derecho, sin los cuales se puede asegurar que los niños/as no ejercen o no han podido ejercer los mismos.

En este marco, la metodología para medir la pobreza infantil propuesta en el presente trabajo considera seis dimensiones fundamentales de derecho: (a) Derecho a la alimentación, (b) Derecho al saneamiento, (c) Derecho a una vivienda digna, (d) Derecho a la educación, (d) Derecho a la información y (e) Derecho a la salud. Cabe señalar que en la propuesta realizada por CEPAL y UNICEF no se considera la dimensión salud. Sin embargo, otras metodologías para medir la pobreza infantil sí la consideran, en tanto entienden que la salud constituye un derecho esencial para afianzar el bienestar del niño, niña y adolescente ${ }^{6}$.

Una vez definidas las dimensiones, se establecieron en una segunda etapa dos grupos de medidas: pobreza infantil extrema cuando se consideran las privaciones severas, y pobreza infantil total, cuando se consideran las

\footnotetext{
5 El Estado nacional ha participado activamente en la construcción de las condiciones para el ejercicio de una plena ciudadanía por parte de la niñez y adolescencia. No sólo adoptó la Convención sobre los Derechos del Niño (ONU, 1989) sino que además asumió compromisos frente a los Objetivos de Desarrollo para el Milenio (ONU, 2000) para el año 2015; y sancionó la Ley de Protección Integral de los Derechos de Niñas, Niños y Adolescentes (Ley 26.061) en 2005. ${ }^{6} \mathrm{El}$ intento más importante para medir la pobreza infantil desde un enfoque multidimensional y de derechos fue realizado en el año 2003 por UNICEF, junto con investigadores de la Universidad de Bristol y de la London School of Economics. Lo anterior a través de un índice, conocido con el nombre Indicador Bristol o Metodología Bristol, que recoge un conjunto de privaciones relacionadas a 7 dimensiones: 1) Nutrición; 2) Acceso al agua potable; 3) Saneamiento; 4) Salud; 5) Vivienda; 6) Educación y 7) Acceso a la información.
} 


\section{SEe}

privaciones moderadas ${ }^{7}$. Es importante advertir que el criterio de identificación se centra en el enfoque de unión, según el cual un niño/a se encuentra en situación de pobreza si presenta al menos una privación en alguna de las dimensiones consideradas.

A continuación, se exponen los umbrales adoptados para cada uno de los indicadores de carencias sociales ${ }^{8}$.

\section{Dimensión: Derecho a la alimentación}

El acceso a una alimentación adecuada constituye un derecho primordial ya que contribuye al sostenimiento de una vida saludable. En este sentido, las privaciones alimentarias en la niñez pueden afectar el desarrollo cognitivo y la capacidad de aprendizaje del niño/a, exponiéndolo a una situación de vulnerabilidad (OMS, 2006; UNICEF, 2009). La situación de riesgo alimentaria, es especialmente grave cuando se presenta en la niñez temprana ( 0 a 4 años), por sus consecuencias en la configuración del cerebro. En estos primeros años, el cerebro se desarrolla a gran velocidad, y configura muchas de sus conexiones neuronales. Los aprendizajes se producen a través de dichas conexiones y el número de sinapsis se multiplica hasta alrededor de los tres años. Si bien existe controversia sobre los años en que se configuran los circuitos neuronales y los tiempos de su maduración, hay consenso en considerar la niñez temprana como el período más sensible.

La propuesta de CEPAL y UNICEF (2012) define las carencias en la dimensión nutricional como la insuficiencia ponderal moderada o baja talla para la edad (desnutrición crónica moderada), y la insuficiencia ponderal grave o baja talla grave en niños y niñas entre 0 y 4 años. Sin embargo, dado que no se cuenta en el marco de la EDSA con dicha información objetiva, se evaluó pertinente el uso de una medida perceptual de riesgo alimentario a nivel de los hogares con niños/as menores de 5 años.

Para el cálculo de esta dimensión, se consideró un índice específico de inseguridad alimentaria, en base a la metodología del Servicio de Investigación Económica del Departamento de Agricultura de los EE.UU (USDA) y a la "Escala Latinoamericana y Caribeña de Seguridad Alimentaria" (ELCSA). En este marco, se consideró como déficit moderado, la situación de los niños/as entre 0 y 4

\footnotetext{
${ }^{7}$ En el ejercicio de medición de pobreza infantil propuesto se utiliza la denominada "línea de corte dual" (Alkire y Foster, 2007), que incluye tanto la definición de umbrales para definir las carencias sociales como un umbral más general que identifica al niño/a pobre en base al número de privaciones.

${ }^{8}$ Un antecedentes de esta aproximación a la medición de la pobreza multidimensional en la infancia argentina se presentó en el Congreso V Congreso de ALAP (Tuñón y González, 2012).
} 


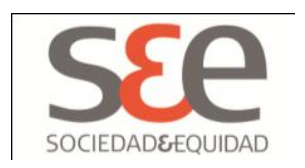

años en hogares en los que se expresó haber reducido la dieta de alimentos en los últimos 12 meses debido a problemas económicos. Asimismo, se consideró déficit severo la situación de los niños/as, en el mismo grupo de edad, en hogares en los que se expresó haber sentido hambre por falta de alimentos en los últimos 12 meses por problemas económicos ${ }^{9}$.

\section{Dimensión: Derecho al saneamiento}

En la definición de la dimensión de referencia se consideraron dos variables: el acceso a agua potable y el tipo de servicio sanitario con el que cuenta la vivienda en la que reside el niño, niña o adolescente. Se entiende que el agua potable constituye un servicio fundamental que tiene un efecto muy importante sobre la calidad de vida de la niñez, en tanto incide directamente sobre las tasas de morbimortalidad infantil (OMS/UNICEF, 2000; OMS, 2006). Asimismo, el tipo de servicio sanitario condiciona de manera directa las condiciones de salubridad de la vivienda.

Por una parte, se define como situación de déficit moderado en la dimensión saneamiento cuando el hogar no tiene acceso a agua corriente, ya que la privación de agua corriente por red constituye un factor de riesgo con alto impacto sobre la transmisión de infecciones y la tasa de mortalidad infantil. Cabe considerar que la Argentina es un país que ha atravesado un proceso de urbanización temprana que lleva más de un siglo, y por lo tanto es de esperar un nivel de desarrollo en infraestructura urbana básica como la que supone el acceso a la red de agua potable ${ }^{10}$. Por ello se evalúa su consideración como indicador de déficit.

\footnotetext{
${ }^{9}$ Se han considerado, adicionalmente, los resultados de estudios locales que han mostrado la relación entre la percepción de hambre -reflejo de la inseguridad alimentaria- y el retardo de crecimiento en talla -reflejo de procesos crónicos de carencias- en niños de 6 meses a 6 años (Bolzán y Mercer, 2009). Con base en estos antecedentes es que se valoró la validez de la inclusión de este indicador en el índice de pobreza multidimensional (PM) como proxy del estado nutricional de la niñez entre 0 y 4 años. Asimismo, en el marco de los estudios del ODSA se realizaron diferentes experiencias de medición de la ELCSA y su adaptación al caso de la Argentina (Adasko, González, 2010; Tuñón, 2010; Salvia, Tuñón, Musante, 2012). Cabe también señalar que la metodología para la medición de la pobreza multidimensional en México incluye esta escala de seguridad alimentaria (CONEVAL, 2010).

${ }^{10} \mathrm{Si}$ bien es conocido que el acceso al agua a través de pozo suele ser la alternativa más frecuente a la red de agua corriente, y esto no significa que el hogar acceda a agua contaminada, también se reconoce que a medida que aumenta la densidad poblacional se eleva el riesgo de contaminación de las aguas de pozo. Dado que la medición de la EDSA se realiza sobre una muestra de grandes aglomerados urbanos (200 mil habitantes y más), se ha considerado la situación de no acceso al agua de red como una privación moderada.
} 


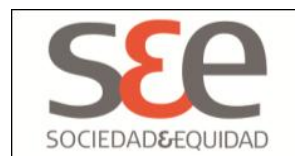

Por otra parte, se considera como una situación de déficit severo cuando el hogar no tiene inodoro o retrete, o cuando lo tiene pero sin descarga de agua. Este indicador constituye una medida de déficit de saneamiento severo en tanto tiene importante impacto epidemiológico especialmente en la niñez.

\section{Dimensión: Derecho a una vivienda digna}

La vivienda constituye el espacio de residencia en donde niños, niñas y adolescentes desarrollan sus actividades cotidianas fundamentales, tales como alimentarse, jugar, descansar, higienizarse, estudiar e interactuar con pares y adultos de referencia. Se comprende que situaciones de hacinamiento 0 precariedad en la construcción de la vivienda pueden limitar el desarrollo del niño/a. Por este motivo, constituye un aspecto relevante que debe ser considerado al momento de analizar la pobreza desde un enfoque multidimensional.

Se ha definido como situación de déficit el que los hogares se instalen en viviendas precarias como son las casillas o ranchos, por no presentar funciones básicas de aislamiento hidrófugo, resistencia, delimitación de los espacios, aislación térmica, acústica y protección superior contra las condiciones atmosféricas. Pero cabe señalar que se establece una distinción entre la situación moderada y la severa. La primera considera a aquellas viviendas construidas con material de adobe con o sin revoque, o que tienen ladrillos sin revocar; mientras que el déficit severo considera a aquellas viviendas de madera, chapa de metal o fibrocemento, chorizo, cartón, palma, paja o materiales de desechos.

Para el indicador de hacinamiento, se consideró en déficit moderado a los hogares con 3 ó 4 personas por cuarto habitable, mientras que para el caso severo, se consideró a aquellos con 5 o más personas por cuarto habitable.

Antes de describir la siguiente dimensión, resulta importante señalar que estas tres primeras dimensiones, en las que se consideran situaciones de riesgo alimentario y condiciones esenciales del hábitat de vida de los niños, niñas y adolescentes, son contempladas en numerosos instrumentos legales y en tal sentido constituyen dimensiones de derechos ${ }^{11}$.

\section{Dimensión: Derecho a la salud}

El acceso a la salud tiene la característica de ser, por un lado, derecho en sí mismo (Convención sobre los Derechos del Niño, ONU, 1989, Art. 24) y, por el

\footnotetext{
${ }^{11}$ Estas dimensiones se encuentran presentes como derechos humanos y sociales en los siguientes instrumentos legales, artículos e incisos: Constitución Nacional, Art. 41, Art. 75 inciso 22; Convención sobre los derechos del niño Art. 6, 24,27; Convención interamericana de Derechos humanos Art. 4, 19, 27; Ley 26.061 de Protección Integral de los Derechos de los Niños, Niñas y Adolescentes, Art. 8 14, 21, 26.
} 


\section{SEe}

otro, condición habilitante para el ejercicio de otros derechos. En este sentido, los controles periódicos y la asistencia médica en la infancia y adolescencia constituyen derechos inalienables que deben ser garantizados para el sostenimiento de la vida humana.

Establecer cuáles son los umbrales de déficit en la atención de la salud del niño/a y adolescente no parece sencillo en el marco de una sociedad en la que existe un servicio público de atención integral de la misma. Aún así, se considera que existen situaciones de vulnerabilidad de este derecho que pueden ser observadas.

En la Argentina existe un amplio calendario de vacunas obligatorias para la infancia y de aplicación gratuita. Lo anterior debido a que la situación de niños/as y adolescentes que no tienen todas las vacunas correspondientes a su edad ha sido definida como indicador de déficit severo en el ejercicio del derecho a la salud.

Por otra parte, existe consenso en las recomendaciones en torno a los controles de salud durante la niñez y adolescencia. En efecto, durante los primeros 6 meses de vida se sugieren controles mensuales, y entre los 6 a los 18 meses controles cada tres meses. De los 18 a los 30 meses los controles deben efectuarse cada seis meses y a partir de los 3 y 4 años una vez al año. En el caso particular de los adolescentes, la Asociación Argentina de Pediatría, recomienda al menos dos controles clínicos al año durante la pubertad y uno al año durante la adolescencia media y tardía ${ }^{12}$.

En este sentido, se define como situación de déficit moderado el que los niños/as entre 0 y 17 años no hayan realizado una consulta médica en los últimos 12 meses o nunca hayan consultado y adicionalmente no tengan cobertura de salud a través de obra social, mutual o prepaga. ${ }^{13}$ Mientras que la situación de déficit severo considera a aquellos niños/as y adolescentes que no tienen todas las vacunas correspondientes a su edad.

\footnotetext{
${ }^{12}$ Ver recomendaciones en: 〈http://www.sap.org.ar/comu-temas-72-cuidado_salud.php $>$

${ }^{13}$ Si bien en la Argentina existe un servicio de salud público, su sola existencia no garantiza el derecho a la atención de la salud. Diversos estudios señalan que, pese a la calidad y excelencia de los profesionales de la salud, los servicios de salud públicos se encuentran en situación de colapso, debido en gran medida a la conjunción de aumento de demanda, falta de recursos humanos, insumos, equipamiento, entre otros (Sancevich, 2006; Niccolini y Cárcova, 2009). El acceso a la atención en salud presenta importantes desigualdades sociales y se consideró que la doble condición de no haber consultado al médico en el período de 12 meses y no acceder a una cobertura de salud a través de obra social, mutual o prepaga constituye una situación de vulnerabilidad a la atención de la salud. En esta situación de vulnerabilidad social se encontraba el $25,4 \%$ de los niños/as y adolescentes del primer quintil de ingresos en 2011 (1,8\% en el $5^{\circ}$ quintil) y el 20,8\% de ellos en los hogares situados bajo la línea de pobreza (6,9\% en hogares no pobres).
} 


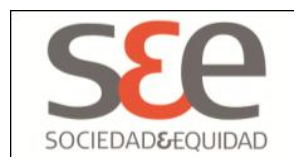

\section{Dimensión: Derecho a la educación}

La educación constituye un derecho habilitante, que promueve el ejercicio de otros derechos. Por este motivo se considera que tiene un valor intrínseco e instrumental en el desarrollo humano para la superación de la pobreza, la desigualdad y la promoción de una cultura común, por lo que resulta fundamental su incorporación en la definición de la pobreza infantil.

En esta dimensión, se define como situación de déficit moderado cuando los niños, niñas y adolescentes entre 5 y 17 años asisten a la escuela con rezago educativo, es decir, habiendo repetido al menos un año escolar y transitan el ciclo educativo con mayor edad que la correspondiente al año en curso. ${ }^{14} \mathrm{Se}$ considera situación de déficit severo cuando los niños, niñas y adolescentes pertenecientes al mismo rango de edad, no asisten a la escuela o nunca han asistido. Cabe señalar que se consideró como grupo de edad 5-17 años, pues la escolarización es obligatoria en la Argentina para esta población (desde sala de 5 años en el nivel inicial hasta el último año de la escuela secundaria).

En esta dimensión se considera el derecho a la educación que está presente en la Constitución Nacional, Art. 14; en la Convención sobre los Derechos del Niño ONU, 1989, Art. 28, 29; en la Ley 26.061 de Protección Integral de los Derechos de los Niños, Niñas y Adolescentes Art. 15; y en la Ley Nacional de Educación 26.206 Art. 11, 16, 18, 19, 26, 29.

\section{Dimensión: Derecho a la información}

En esta dimensión se considera el derecho a la información (Convención sobre los Derechos del Niño, ONU, 1989, Art. 17), que adquiere particular relevancia en los procesos de socialización de la niñez y adolescencia. Un modo de aproximación a esta dimensión es la exposición a medios de comunicación, que son vías de acceso a la información y vías donde adquirir herramientas de expresión y participación social.

En esta dimensión se proponen los siguientes indicadores: tener teléfono en el hogar (fijo o celular), acceso a internet y biblioteca (o libros infantiles). En relación a los mismos se considera en situación de déficit moderado a aquellos niños/as que habitan hogares en los que al menos dos de los indicadores de referencia estén ausentes. La situación de déficit severo será la de aquellos

\footnotetext{
14 No son pocas las investigaciones en el campo educativo que advierten sobre la mayor propensión a la deserción escolar entre los niños/as y adolescentes que han repetido algún año (Cerrutti y Binstock, 2004; López, 2001; Herrán y Van Uythem 2001). Estos conocimientos incluso son fundamento de una reciente resolución del Consejo Federal de Educación (2011:6) en la que se considera que "el Estado debe garantizar los derechos educativos de todos los niños y niñas y que por tanto, le cabe la obligación de actuar frente a toda situación que menoscabe las posibilidades de aprender de los mismos" como puede ser el repetir los primeros años de la educación primaria. Asimismo, cabe señalar que el indicador de rezago educativo también es considerado en el índice desarrollado por el CONEVAL (2010).
} 


\section{SEe}

que habitan hogares donde no acceden a ninguno de los bienes y servicios anteriormente mencionados.

\begin{tabular}{|c|c|c|c|}
\hline \multicolumn{4}{|c|}{ FIGURA I. INDICADORES Y UMBRALES DE PRIVACIÓN } \\
\hline VARIABLE & DIMENSIÓN & MODERADO & SEVERO \\
\hline \multirow{5}{*}{ HOGAR } & $\begin{array}{l}\text { SANEAMIENTO } \\
\text { (0-17 AÑOS) }\end{array}$ & $\begin{array}{l}\text { Niños, niñas y adolescentes en viviendas que } \\
\text { no acceden a agua corriente }\end{array}$ & $\begin{array}{l}\text { Niños, niñas y adolescentes en viviendas } \\
\text { con inodoro sin descarga de agua o que no } \\
\text { disponen de inodoro }\end{array}$ \\
\hline & \multirow[b]{2}{*}{$\begin{array}{l}\text { VIVIENDA } \\
\text { ( 0-17 AÑOS) }\end{array}$} & $\begin{array}{l}\text { Hacinamiento: niños/as en viviendas con tres } \\
\text { o cuatro personas por cuarto habitable. }\end{array}$ & $\begin{array}{l}\text { Hacinamiento: niños/as en viviendas con } \\
\text { cinco o más personas por cuarto habitable. }\end{array}$ \\
\hline & & $\begin{array}{l}\text { Calidad de la vivienda: niños/as que habitan en } \\
\text { viviendas de adobe con o sin revoque, o que } \\
\text { tienen ladrillos sin revocar. }\end{array}$ & $\begin{array}{l}\text { Calidad de la vivienda: niños/as que habitan } \\
\text { en viviendas de madera, chapa de metal o } \\
\text { fibrocemento, chorizo, cartón, palma, paja o } \\
\text { materiales de desechos. }\end{array}$ \\
\hline & $\begin{array}{l}\text { INFORMACIÓN } \\
(0-17 \text { AÑOS })\end{array}$ & $\begin{array}{l}\text { Niños, niñas y adolescentes en viviendas sin } \\
\text { al menos dos de los siguientes componentes: } \\
\text { teléfono (fijo o celular), internet, biblioteca o } \\
\text { libros infantiles }\end{array}$ & $\begin{array}{l}\text { Niños, niñas y adolescentes en viviendas } \\
\text { que no acceden a ninguno de los siguientes } \\
\text { componentes: teléfono (fijo o celular). } \\
\text { internet, biblioteca o libros infantiles }\end{array}$ \\
\hline & $\begin{array}{l}\text { ALIMENTACIÓN } \\
(0-4 \text { AÑOS) }\end{array}$ & $\begin{array}{l}\text { Niños y niñas en hogares en los que se } \\
\text { expresa haber reducido la dieta de alimentos } \\
\text { en los últimos } 12 \text { meses por problemas } \\
\text { económicos. }\end{array}$ & $\begin{array}{l}\text { Niños y niñas en hogares en los que se } \\
\text { expresa haber sentido hambre por falta de } \\
\text { alimentos en los uiltimos } 12 \text { meses por } \\
\text { problemas económicos. }\end{array}$ \\
\hline \multirow[t]{2}{*}{$\begin{array}{l}\text { NIÑOS/AS Y } \\
\text { ADOLESCENTES }\end{array}$} & $\begin{array}{l}\text { SALUD } \\
\text { (0-17 AÑOS) }\end{array}$ & $\begin{array}{l}\text { Niños, niñas y adolescentes que hace un año o } \\
\text { más que no realizan una consulta médica y no } \\
\text { tienen cobertura de salud (obra social, mutual } \\
\text { o prepaga) }\end{array}$ & $\begin{array}{l}\text { Niños, niñas y adolescentes que no tienen } \\
\text { todas las vacunas correspondientes a su } \\
\text { edad }\end{array}$ \\
\hline & \begin{tabular}{|l} 
EDUCACIÓN \\
(5-17 AÑOS)
\end{tabular} & $\begin{array}{l}\text { Niños, niñas y adolescentes que asisten a la } \\
\text { escuela con sobre edad. }\end{array}$ & $\begin{array}{l}\text { Niños, niñas y adolescentes que no asisten a } \\
\text { la escuela }\end{array}$ \\
\hline
\end{tabular}

\section{Incidencia de la pobreza en la infancia y adolescencia urbana en la Argentina}

La incidencia de la pobreza multidimensional o tasa de pobreza ${ }^{15}$, permite identificar el porcentaje de niños/as menores de 18 años en hogares que presentan privaciones o carencias sociales. De esta forma, la pobreza infantil total constituye una medida de exclusión en tanto permite identificar a los niños/as que están privados de derechos fundamentales para su desarrollo.

En el año 2011, se estima que el $12,9 \%$ de los niños/as y adolescentes en la Argentina urbana pertenecía a hogares que experimentaban privaciones severas en alguna de las dimensiones de derechos consideradas; mientras que un $13,7 \%$ pertenecía a hogares con privaciones moderadas. Esto muestra que el

${ }^{15}$ El índice de recuento (tasa de pobreza) es una de las tres medidas propuestas por Bourguignon y Chakravarty (2003), las cuales se encuentran inspiradas en la desarrollada por Foster, Greer y Thorbecke (1984):

$H=\frac{1}{n} \sum_{i \in S_{j}}\left(\sum_{j=1}^{m} a_{j} S_{j}^{i}\left(1-\frac{x_{i j}}{z_{j}}\right)\right)^{0}=\frac{1}{n} \sum_{i=1}^{q}\left(\sum_{j=1}^{m} a_{j} S_{j}^{i}\left(1-\frac{x_{i j}}{z_{j}}\right)\right)^{0}=\frac{q}{n}$ 


\section{S\&e \\ SOCIEDADEEQUIDAD}

$26,6 \%$ de los niños/as y adolescentes se encontraba en hogares pobres en términos multidimensionales (ver figura II), lo que implica que estos niños/as vieron vulnerados al menos uno de los derechos fundamentales, tales como saneamiento, vivienda adecuada, alimentación, salud, educación y acceso a la información.

El análisis por dimensión de derechos permite reconocer que en el campo del saneamiento, la vivienda y la alimentación, las deudas sociales con la niñez y adolescencia son especialmente significativas (ver figura III). Particularmente en cuanto al derecho a vivir en un hábitat con condiciones adecuadas de saneamiento se advierte que un $18 \%$ de los niño/as entre 0 y 17 años presentaban déficit moderado, es decir, pertenecían a hogares sin acceso al agua potable por red; mientras que el $11,4 \%$ de los niños/as y adolescentes se encontraba en hogares con privaciones graves, es decir, en hogares que no tenían inodoro o retrete, o que carecían de descarga de agua.

Asimismo, se estima que el $17,8 \%$ de los niños, niñas y adolescentes se encontraba en hogares en situación de déficit moderado en la dimensión de vivienda y el $4,9 \%$ en situación severa. Alrededor de dos de cada diez niños/as y adolescentes residían en viviendas precarias en términos de su construcción y en condiciones de hacinamiento.

Al descomponer la importancia relativa de las distintas dimensiones de derechos en el porcentaje de extrema pobreza infantil, se advierte que las carencias sociales más relevantes pertenecen al espacio del hábitat. En particular se destacan: saneamiento $(43 \%)$, y vivienda $(18,4 \%)$, tomando en cuenta que ambas explican un 61,4\% de la pobreza severa (ver figura IV).

Poder advertir que en el espacio del hábitat de vida físico del niño/a y adolescente se registra una de las principales carencias sociales parece un dato relevante en términos del diseño de políticas públicas. En particular si se reconoce la impronta negativa de un hábitat insalubre en el ejercicio de otros derechos como son el derecho a la salud, la educación y otros procesos de integración social. Son conocidos los riesgos que supone el déficit de agua segura y los problemas de saneamiento en la salud de la niñez y en particular en la infancia temprana en términos de mayor predisposición a la adquisición de enfermedades, muchas de ellas letales.

No contar con espacio suficiente para todos los miembros del hogar, así como habitar en condiciones de precariedad en términos de la calidad de la construcción, no sólo restringe las oportunidades de socialización de los niños/as (el espacio de juego, de estudio, de encuentro con amigos, entre otros), sino que expone a los niños/as a situaciones de maltrato, negligencia y promiscuidad. Es fácil advertir que las características del hábitat de vida del niño/a comprometen el sostenimiento de la vida en los primeros años, así como aspectos fundamentales del desarrollo social. La familia en tanto agencia primaria de socialización tiene como principal espacio de convivencia la vivienda y el barrio. Las características del hábitat de vida condicionan 


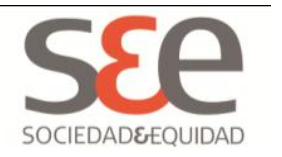

aspectos claves en el campo de las necesidades y capacidades humanas: poder estudiar, ser acompañado en el proceso de formación, jugar con otros miembros del hogar, invitar amigos, entre otros.

En este sentido, poder reconocer el espacio de las privaciones en el hábitat de vida y su relación con el ejercicio de otros derechos puede ser considerado una ventana de oportunidad sobre la cual orientar la acción de los Estados. Los cambios que se producen en el espacio del hábitat son cambios permanentes, menos sensibles a las eventuales crisis socioeconómicas, y fundamentales en la vida de la infancia, pues tienen consecuencias positivas de corto plazo tanto en la salud como en los procesos de socialización y de mediano plazo en los logros educativos.

Las metas relacionadas con el agua segura y el saneamiento deben ser consideradas en su integralidad, ya que parte de la solución del problema depende de los Estados en términos de provisión de la infraestructura barrial. No obstante, en situación de pobreza el problema no logra ser solucionado si no se garantiza la infraestructura necesaria en el interior de las viviendas en términos de conexión y acceso real al servicio. Las políticas de transferencia de ingresos aplicadas en la región y en particular en la Argentina con la Asignación Universal por Hijo son necesarias pero no suficientes para incidir en aspectos estructurales de la vida de las familias y en particular de los hogares con niños/as.

Otra dimensión de derechos clave al sostenimiento de la vida es el derecho a la alimentación. Resulta paradójico que en países como la Argentina, productores de alimentos para el mundo, el 20,8\% de los niños/as menores de 5 años se encuentre en situación de riesgo alimentario $(10,1 \%$ con privación moderada y $10,7 \%$ con privación severa). Esto revela que el problema de la alimentación no es un problema de falta de alimentos, sino de acceso a los alimentos en cantidad y calidad, y en condiciones socialmente aceptadas.

Existe amplio consenso sobre los efectos regresivos de las privaciones alimentarias en los primeros años de vida, tanto en el desarrollo físico como cognitivo del niño/a. Los efectos de la desnutrición infantil en este período sensible pueden alcanzar consecuencias irreversibles, y en tal sentido, un límite para el acceso a recursos educativos y sociales esenciales para el mejor aprovechamiento de oportunidades. Si bien el acceso a los alimentos tiene una vinculación innegable con los ingresos económicos de los hogares, es esperable que las políticas de transferencia de ingresos tengan un efecto positivo, aunque probablemente sea menor en contextos de alta inflación como el que experimenta Argentina. Parece necesario entonces señalar que no es un problema asociado únicamente a la pobreza de ingresos, ya que existen otros factores exógenos (macroeconómicos y socioculturales) y endógenos (nivel educativo de la madre, tamaño de la familia, tipo de hogar, entre otros) a las estrategias de reproducción de los hogares que cooperan con dicha situación de vulnerabilidad y que requieren ser consideradas en el diseño de políticas 


\section{SEe}

públicas destinadas a los hogares, en particular orientadas a los hogares con niños/as.

En la sociedad argentina, los derechos a la salud y a la educación parecen estar garantizados por el carácter de gratuidad de dichos servicios. Pese a lo anterior, que exista una oferta pública no significa que todos accedan y que la calidad del servicio sea la misma para todos/as. Tanto es así que se estima que un $11,5 \%$ de la niñez y adolescencia urbana no había realizado una consulta médica durante el 2011, o nunca lo había hecho. Tampoco tenían cobertura de salud a través de obra social, mutual o prepaga. El 2,1\% no tenía completo el calendario de vacunas correspondientes a su edad de aplicación, la cual es gratuita y obligatoria.

En relación con el derecho a la educación, se estima que un $12,2 \%$ de los niños/as entre 5 y 17 años presentaba rezago educativo $(8,7 \%$ en entre 5 y12 años y $19,6 \%$ entre 13 y 17 años), y que $4,7 \%$ de los niños/as de la misma edad no asistía a la escuela o nunca había asistido (1,5\% entre 5 y12 años y $9 \%$ entre 13 y 17 años). Esto manifiesta que alrededor de un $17 \%$ de niños/as y adolescentes se encontraba en una situación de déficit educativo $(10,2 \%$ entre los 5 a 17 años y $28,6 \%$ entre los 13 a 17 años) el año del estudio.

Si bien en ninguno de los casos se están considerando indicadores de calidad, lo cual representa un límite del instrumento construido, se logra una aproximación a la población infantil y adolescente en situación de riesgo. Puede medirse la población que no está participando del sistema de salud en cuanto a la prevención de enfermedades, y también la que se encuentra en una situación de rezago escolar, es decir, quienes están en riesgo de no finalizar el ciclo educativo obligatorio.

Por último, en la dimensión del derecho a la información, se realiza una aproximación a la oportunidad de acceso, pues se indaga sobre un conjunto de recursos a los que pueden o no acceder los hogares y por ende los niños/as y adolescentes integrantes de los mismos. Se estima que $27,2 \%$ de los niños, niñas y adolescentes no tenía al menos dos de los siguientes bienes y servicios asociados al acceso a la información en el ámbito de su hogar: teléfono (fijo o celular), internet, biblioteca (o libros infantiles); y sólo $2 \%$ no accedía simultáneamente a ninguno de ellos. Si bien los indicadores de acceso no indican el uso de los mismos por parte de los niños/as, ellos permiten reconocer la estructura de oportunidades disponible para poder ejercer su derecho a expresarse, hacerse oír, participar de la comunidad, acceder al conocimiento, recibir y dar información, entre otras formas de participación social. 


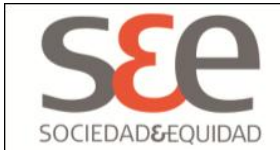

FIGURA II. INCIDENCIA DE LA POBREZA INFANTII

En porcentaje de niños, niñas y adolescentes entre 0 y 17. Año 2011

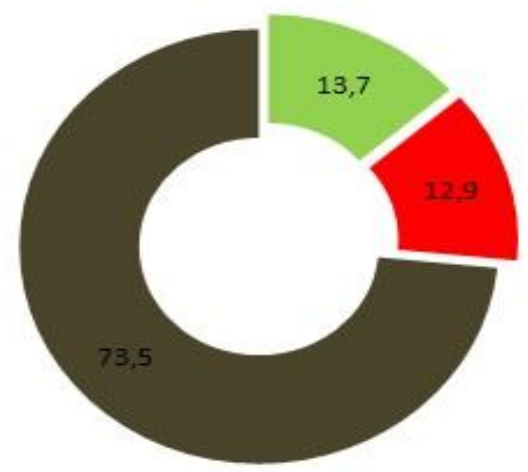

1] Pobre moderado

- Pobre severo

No pobre

Fuente: Elaboración propia con base en datos de la EDSA-Bicentenario (2010-2016). Año 2011. Obervatorio de la Deuda Social Argentina(ODSA- UCA)

\section{FIGURA III. PRIVACIONES SOCIALES*}

En porcentaje de niños, niñas y adolescentes entre 0 y 17. Año 2011

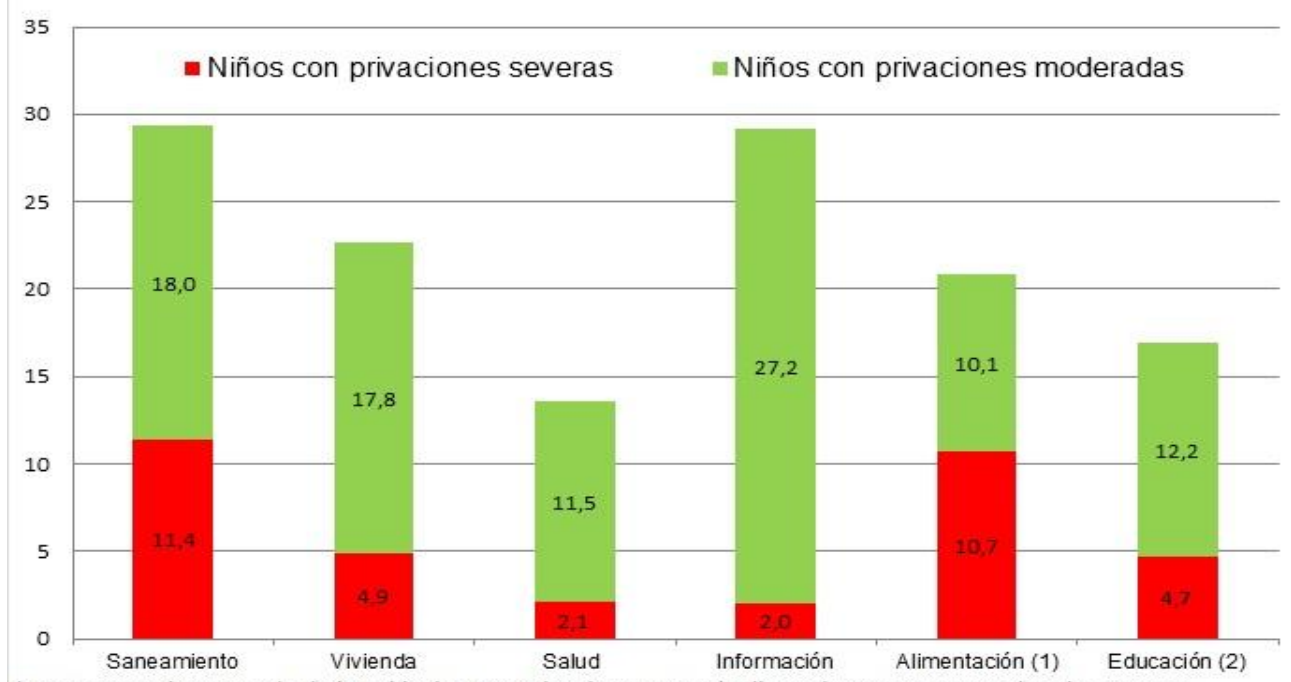

* Se reporta el porcentaje de la población con privaciones en cada dimensión según sea moderada o severa

(1) Se considera a los nirios/as entre 0 y 4 años.

(2) Se considera a los niños/as y adolescentes entre 5 y 17 años.

Fuente: Elaboración propia con base en datos de la EDSA-Bicentenario (2010-2016). Año 2011.Obervatorio de la Deuda Social Argentina(ODSA- UCA)

Tal como mencionamos anteriormente, en la descomposición de la importancia relativa de las distintas dimensiones de derechos en el interior de la extrema pobreza infantil se advierte que las carencias sociales más 


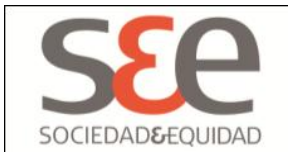

relevantes pertenecen al espacio del hábitat (ver figura IV). Es posible distinguir en el interior de esta misma población a aquellas que experimentan más privaciones sociales de aquellas que presentan menos privaciones. Se advierte que el $26,6 \%$ registra al menos una carencia social, el 6,3\% presenta al menos dos carencias sociales y el $2,3 \%$ al menos tres privaciones. La población que presenta 4 o más carencias $(0,1 \%)$ constituye un porcentaje marginal (ver figura V).

\section{FIGURA IV. INDICADORES DE INCIDENCIA: CONTRIBUCIÓN POR DIMENSIÓN A LA EXTREMA POBREZA}

En porcentaje de niños, niñas y adolescentes entre 0 y 17. Año 2011

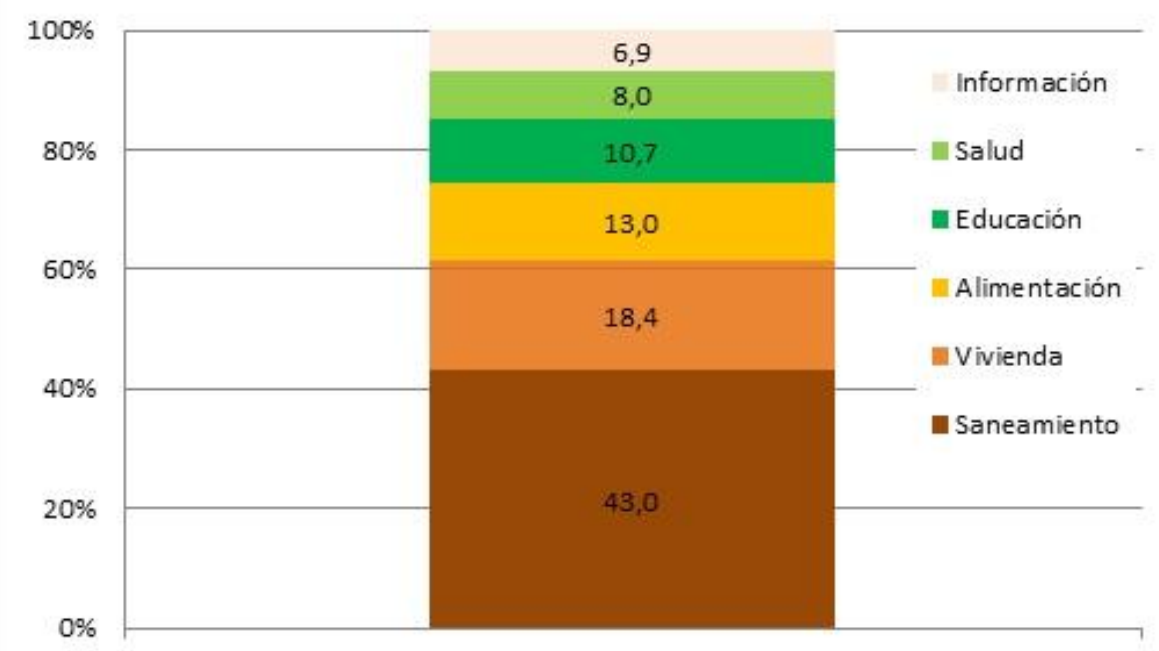

Fuente: Elaboración propia con base en datos de la EDSA-Bicentenario (2010-2016). Año 2011. Obervatorio de la Deuda Social Argentina (ODSA- UCA) 


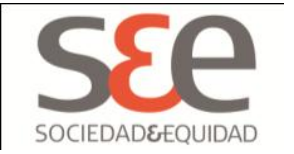

\section{FIGURA V. PORCENTAJE ACUMULADO DE LA POBLACIÓN QUE PRESENTA AL MENOS UNA CARENCIA SOCIAL O MÁS \\ En porcentaje de niños, niñas y adolescentes entre 0 y 17. Año 2011}

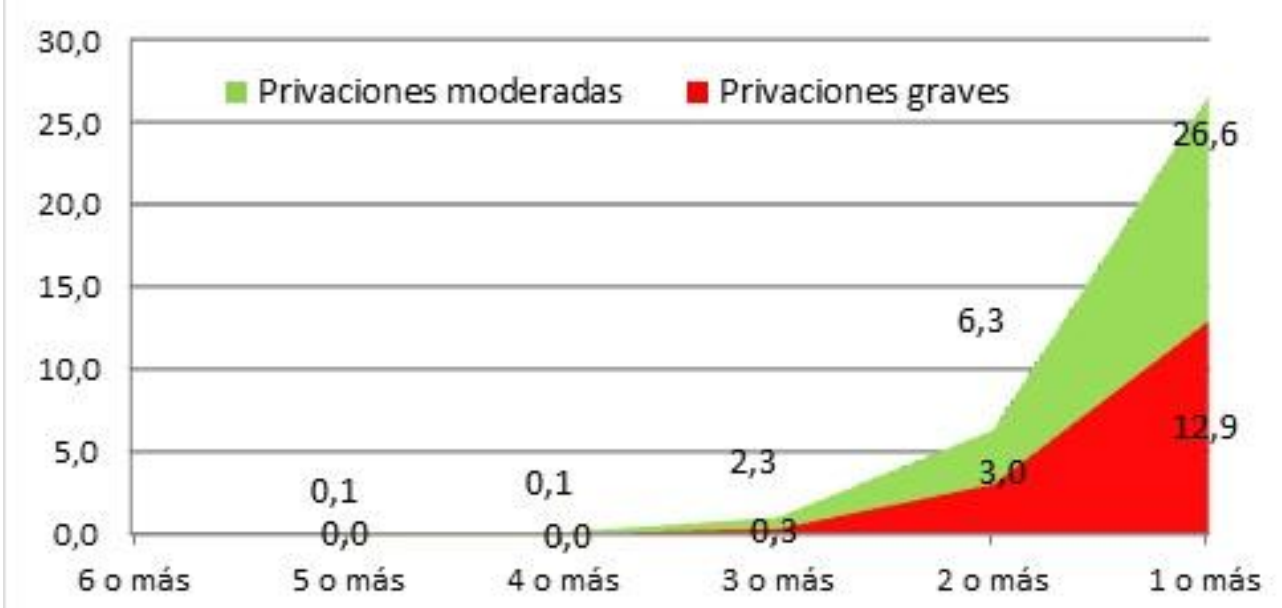

Fuente: Elaboración propia con base en datos de la EDSA-Bicentenario (20102016). Año 2011. Obervatorio de la Deuda Social Argentina (ODSA- UCA)

Por último, y tras haberse realizado el cálculo de la incidencia de la pobreza a través del índice de recuento, resulta interesante reconocer y analizar los principales factores sociodemográficos, sociales y geográficos asociados a la pobreza multidimensional en la niñez y adolescencia urbana ${ }^{16}$ (ver figura $\mathrm{Vl}$ ).

Más específicamente, y en relación al espacio socioresidencial, se advierte que a medida que empeoran las condiciones de éste, se incrementa la propensión a la pobreza. También advertimos que los niños/as y adolescentes en el espacio residencial informal de villa o asentamiento urbano, presenta 8,8 veces más oportunidad de experimentar privaciones moderadas que sus pares en el espacio residencial formal medio, y 3 veces más riesgo de privaciones severas.

En relación al espacio geográfico, la situación más crítica se encuentra en el Conurbano Bonaerense (31\%). En contraposición, son los niños/as que

\footnotetext{
${ }^{16}$ Es importante destacar que este análisis, si bien permite identificar las variables que están asociadas con la situación de pobreza, no permite señalar las causas de la misma. Para esto es necesario realizar regresiones multivariadas de los determinantes de la probabilidad de ser pobre.
} 


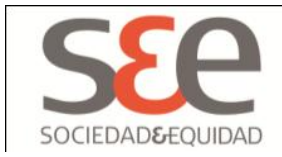

viven en la ciudad de Buenos Aires los que se encuentran en mejor situación relativa en términos de carencias sociales $(15,7 \%)$.

Entre los niños/as en hogares cuya madre no finalizó la escuela secundaria la propensión a la pobreza multidimensional es 3 veces superior a la registrada en pares cuya madre finalizó la escuela media o logró mayores credenciales educativas. Las brechas de desigualdad regresivas para los primeros son de 4,7 veces en las privaciones moderadas y de 2 veces en las severas.

No se advierten diferencias significativas en la propensión a la pobreza multidimensional según el sexo de los niños/as. Sin embargo, la vulnerabilidad es mayor en los niños/as menores de 5 años y en los adolescentes que en los niños/as en edad escolar ( 5 a 12 años). Probablemente esto se deba entre los primeros a su pertenencia a hogares con progenitores jóvenes y en el caso de los adolescentes a la mayor propensión a pertenecer a hogares más numerosos. Justamente, los niños/as en hogares cuya madre es menor a 25 años tienen mayor propensión a la pobreza, así como se multiplica dicha propensión a medida que aumenta la cantidad de miembros niños/as en el hogar.

Otro factor asociado a las múltiples privaciones es el socio-ocupacional. Los niños/as en hogares cuyo jefe/a se encuentra desempleado, subempleado o en empleos precarios, registran mayor propensión a la pobreza que pares cuyos adultos de referencia tienen empleos plenos de derechos. Asimismo, los niños/as y adolescentes que realizan trabajos domésticos intensivos 0 actividades económicas, registran mayor propensión a la pobreza que sus pares que no trabajan (los primeros registran una brecha regresiva respecto de los segundos de 2 veces en las privaciones moderadas y de 1,7 veces en las severas).

En relación a la situación de precariedad en las inserciones ocupacionales, también se advierte mayor propensión a la pobreza entre los chicos/as pertenecientes a hogares que reciben la AUH $u$ otros planes sociales. Esto es esperable en la medida que se trata de programas sociales orientados a sectores que carecen de inserciones plenas en el mercado de trabajo.

En resumen, la propensión a la pobreza y en particular a las privaciones severas, son mayores entre los niños/as y adolescentes del Conurbano Bonaerense y en espacios de villas o asentamientos urbanos, donde las deudas con respecto a las condiciones del hábitat de vida están pendientes. Asimismo, la gravedad de la pobreza es más probable en los hogares con bajo clima educativo, jóvenes en términos de la edad de los cónyuges, numerosos en cantidad de miembros niños/as, y en los que la inclusión en el mundo del trabajo son precarias e incluyen la mano de obra infantil. 


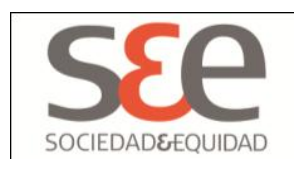

FIGURA VI. POBREZA MULTIDIMENSIONAL SEGÚN CARACTERÍSTICAS SELECCIONADAS

En porcentaje de niños, niñas y adolescentes entre 0 y 17. Año 2011

\begin{tabular}{|c|c|c|c|}
\hline & Pobreza Total & $\begin{array}{c}\text { Pobreza } \\
\text { moderada }\end{array}$ & $\begin{array}{c}\text { Pobreza } \\
\text { severa }\end{array}$ \\
\hline TOTAL & 26,5 & 13,7 & 12,9 \\
\hline \multicolumn{4}{|l|}{ AGLOMERADOS URBANOS } \\
\hline$\overline{A M B A}$ & 28,2 & 15,0 & 13,2 \\
\hline Ciudad Autónoma de Buenos Aires & 15,7 & 7,0 & 8,7 \\
\hline Conurbano Bonaerense & 31,0 & 16,8 & 14,2 \\
\hline Total Urbano Interior & 23,9 & 13,7 & 12,9 \\
\hline \multicolumn{4}{|l|}{ CONDICIÓN RESIDENCIAL } \\
\hline Urbanización informal & 62,1 & 41,4 & 20,6 \\
\hline Urbanización formal de nivel bajo & 29,1 & 14,1 & 15,0 \\
\hline Urbanización formal de nivel medio & 11,4 & 4,7 & 6,8 \\
\hline \multicolumn{4}{|l|}{ CLIMA EDUCATIVO DE LA MADRE } \\
\hline Hasta secundario incompleto & 37,9 & 21,2 & 16,7 \\
\hline Secundario completo y superior & 12,5 & 4,5 & 8,0 \\
\hline \multicolumn{4}{|l|}{ EDAD DE LA MADRE } \\
\hline Hasta 24 años & 33,7 & 16,8 & 16,9 \\
\hline 25 a 45 años & 24,9 & 12,5 & 12,4 \\
\hline 46 y más & 25,4 & 15,1 & 10,3 \\
\hline \multicolumn{4}{|l|}{ OCUPACIÓN DEL JEFE } \\
\hline Inactivo & 30,1 & 19,5 & 10,5 \\
\hline Desempleado-subempleado & 43,6 & 25,6 & 18,0 \\
\hline Precario & 34,4 & 19,7 & 14,7 \\
\hline Pleno & 18,1 & 7,0 & 11,2 \\
\hline \multicolumn{4}{|l|}{ TIPO DE HOGAR } \\
\hline Resto & 25,5 & 13,2 & 12,3 \\
\hline Monopaternal & 31,3 & 15,8 & 15,5 \\
\hline \multicolumn{4}{|l|}{ CANTIDAD DE NIÑOS EN EL HOGAR } \\
\hline 1 a 2 & 19,3 & 10,0 & 9,3 \\
\hline 3 a 4 & 31,4 & 15,2 & 16,2 \\
\hline 5 o más & 48,2 & 27,6 & 20,6 \\
\hline \multicolumn{4}{|l|}{ ASISTENCIA SOCIAL } \\
\hline $\begin{array}{l}\text { Salario familiar/Autónomos/Asalariados con } \\
\text { ingresos superiores a } \$ 5200\end{array}$ & 17,1 & 7,1 & 10,0 \\
\hline $\begin{array}{l}\text { Asignación Universal por Hijo (AUH)/ otros } \\
\text { planes sociales }\end{array}$ & 40,8 & 21,4 & 19,5 \\
\hline Sin asistencia & 22,5 & 14,9 & 7,5 \\
\hline \multicolumn{4}{|l|}{ SEXO DE LOS NIÑOS EN EL HOGAR } \\
\hline Varón & 27,9 & 14,3 & 13,5 \\
\hline Mujer & 25,9 & 13,8 & 12,0 \\
\hline \multicolumn{4}{|l|}{ GRUPO DE EDAD } \\
\hline 0 a 4 años & 29,6 & 12,4 & 17,3 \\
\hline 5 a 12 años & 22,4 & 12,7 & 9,7 \\
\hline 13 a 17 años & 31,4 & 17,8 & 13,5 \\
\hline \multicolumn{4}{|c|}{ TRABAJO INFANTIL: ECONÓMICO Y DOMÉSTICO } \\
\hline No trabaja & 24,3 & 12,5 & 11,8 \\
\hline Trabaja & 44,1 & 24,5 & 19,6 \\
\hline
\end{tabular}

Fuente: Elaboración propia con base en datos de la EDSA-Bicentenario (2010-2016). Año 2011. Obervatorio de la Deuda Social Argentina (ODSA- UCA) 


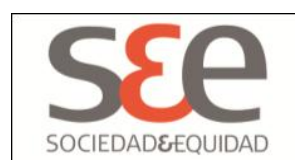

\section{La pobreza infantil multidimensional en relación a la pobreza por ingresos}

Si bien la medición de la pobreza a través de la línea de ingresos constituye un instrumento ampliamente aceptado a escala mundial, también ha sido sujeto a varios cuestionamientos. Esto se debe a que el estudio de la pobreza a partir de la capacidad de los hogares de adquirir bienes y servicios en el mercado parece una medida parcial que requiere de otras aproximaciones complementarias que incorporen un conjunto de satisfactores esenciales para el bienestar de las personas, y en este caso lo específico del desarrollo humano y social de la infancia (CONEVAL, 2010; ONU, 2004).

El estudio desde el enfoque indirecto de la línea de pobreza y el de privaciones múltiples pertenecen a espacios de naturaleza distinta, sin embargo, la combinación de ambas metodologías permite identificar la población vulnerable que tiene problemas de ingresos $\mathrm{y} / \mathrm{o}$ de privaciones sociales en dimensiones de derechos.

A continuación se presenta la incidencia de la pobreza por ingresos y la pobreza multidimensional a nivel de la población de niños, niñas y adolescentes menores de 18 años en la Argentina urbana (ver figura VII).

La estimación de la pobreza por ingresos fue realizada con base en índices de precios alternativos al oficial. Se estima que en el cuarto trimestre del 2011, en Argentina urbana, un 33,1\% de los niños/as y adolescentes menores de 18 años pertenecía a hogares por debajo de la línea de pobreza $\left(24,6 \%\right.$ pobres no indigentes y $8,5 \%$ indigentes). ${ }^{17}$ En tanto la pobreza multidimensional es 6,5 puntos porcentuales inferior a la estimación por ingresos de los hogares y su incidencia severa y moderada registra proporciones similares.

La combinación de ambos tipos de pobreza permite identificar un 11,8\% de los niños/as y adolescentes pertenecientes a hogares que presentan privaciones sociales, pero los ingresos son superiores al valor de la línea de pobreza; en contraposición, se estima que un $18,3 \%$ de los niños/as se encuentra en hogares pobres por ingresos, pero que no presentan carencias sociales. Por último, es pertinente destacar que un $14,7 \%$ de los niños/as de los principales aglomerados urbanos del país se encuentra en hogares con ingresos inferiores al costo de la canasta básica total y que padece privaciones sociales (ver figura VIII).

Un dato relevante surge al comparar la población con pobreza multidimensional extrema y aquella en situación de indigencia por ingresos. Al

\footnotetext{
${ }^{17}$ Se considera pobre a aquel niño/a en hogares cuyos ingresos no superen el umbral del ingreso monetario necesario para adquirir en el mercado el valor de una canasta de bienes y servicios básicos (Canasta Básica Total - CBT). En 2011, la canasta básica total, con la misma composición que la oficial pero valuada a precios relevados en forma independiente en el mercado fue de \$720.- por equivalente adulto (para una familia compuesta por 2 adultos, 1 niño y 1 adolescente equivalente era de \$2.527,2.-, aproximadamente U\$S420).
} 


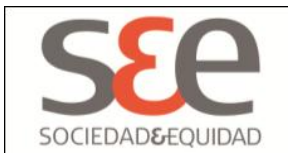

respecto, se advierte que un $10,6 \%$ de los niños, niñas y adolescentes se encuentra en hogares que presentan al menos una privación severa en las dimensiones consideradas, aún cuando los ingresos de estos hogares superan la línea de indigencia. Asimismo, el $6,3 \%$ se encuentra en hogares que son indigentes por ingresos pero que no presentan privaciones sociales. El 2,3\% de los niños/as se encuentra dentro de la población más crítica, en tanto reside en hogares indigentes en términos de ingresos y que además presentan al menos una privación social de tipo severa en las dimensiones consideradas.

En síntesis, se advierte que el $45 \%$ de la niñez y adolescencia urbana en Argentina es pobre en términos de los ingresos de su hogar y/o experimenta privaciones sociales a las cuales tiene derecho. Al tiempo que se estima que un $19,4 \%$ de la niñez y adolescencia es extremadamente pobre en términos de privaciones graves $\mathrm{y} / \mathrm{o}$ indigencia por ingresos (aproximadamente 2.400 .000 niños/as y adolescentes).

FIGURA VII. ESTIMACIÓN DE LA POBREZA INFANTIL SEGÚN MÉTODOS DE MEDICIÓN DE LA POBREZA

En porcentaje de niños, niñas y adolescentes entre 0 y 17. Año 2011

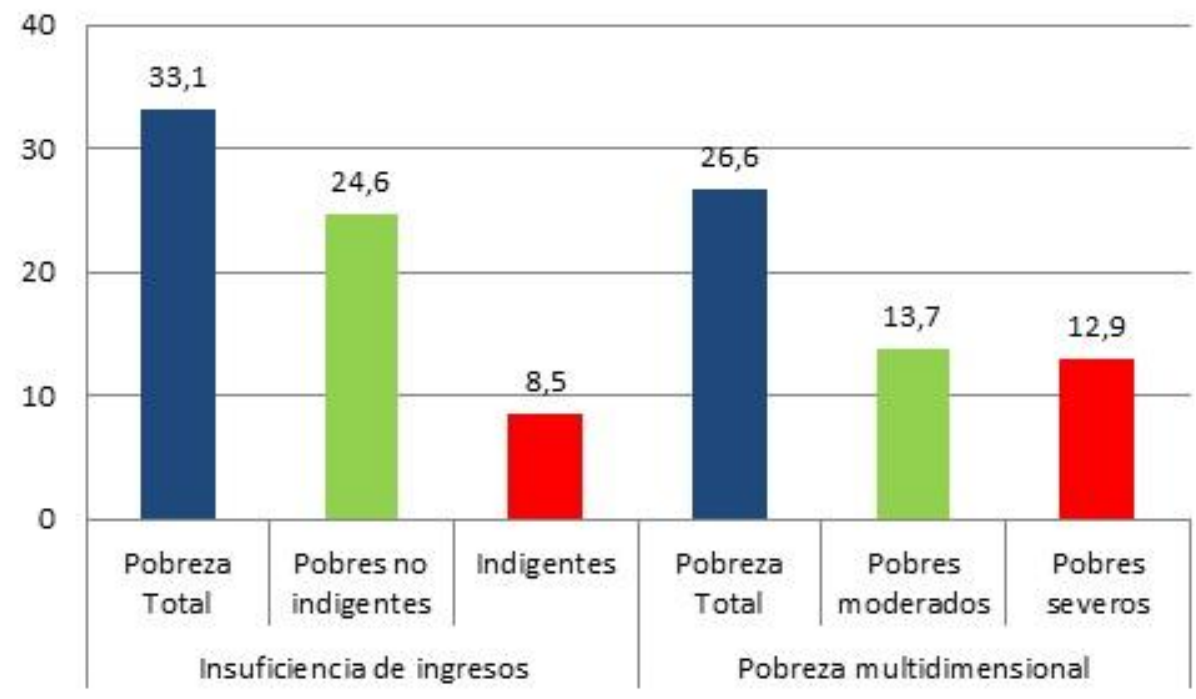

Fuente: Elaboración propia con base en datos de la EDSA-Bicentenario (2010-2016). Año 2011.Obervatorio de la Deuda Social Argentina(ODSA- UCA) 


\section{SEe}

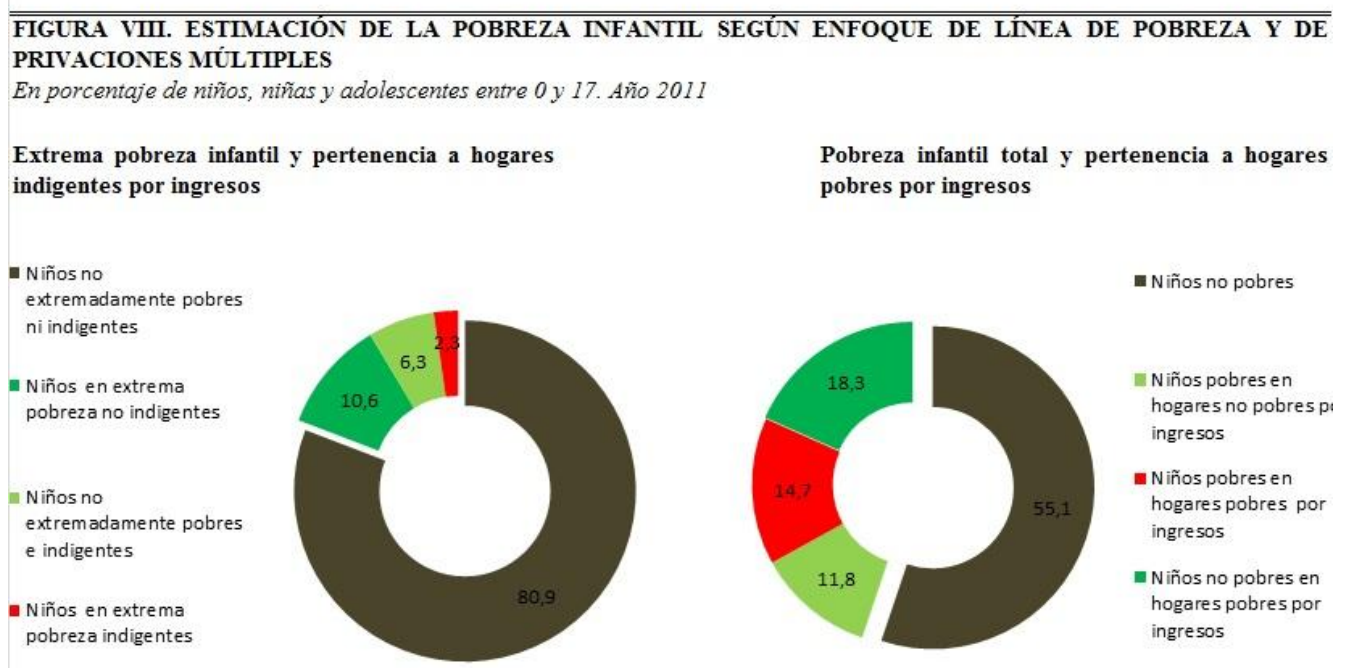

Fuente: Elaboración propia con base en datos de la EDSA-Bicentenario (2010-2016). Año 2011.Obervatorio de la Deuda Social Argentina(ODSA- UCA)

A continuación, se realiza un análisis de la incidencia de la pobreza por ingresos y la pobreza multidimensional a nivel de la población de niños, niñas y adolescentes en la Argentina urbana, según: factores sociodemográficos del niño y del hogar, factores socio educativos, residenciales y de localización geográfica, que se supone inciden sobre la dicha pobreza (ver figura IX).

En relación al espacio geográfico, la combinación de ambos tipos de pobreza permite identificar que el Gran Buenos Aires registra mayores niveles de pobreza multidimensional y por ingresos que el resto de las ciudades urbanas del interior $(15,1 \%$ y $14,2 \%$ respectivamente). También se observa que mientras el porcentaje de niños/as pobres únicamente por carencias sociales es mayor en el Gran Buenos Aires, la pobreza únicamente por ingresos es superior en las ciudades urbanas del interior.

En cuanto al espacio residencial, evidenciamos que la situación más severa se focaliza en el espacio informal de villa o asentamiento, en tanto un $36,3 \%$ de los niños/as pertenece a hogares que registran ambos tipos pobrezas. Este porcentaje se reduce casi 20 puntos porcentuales en los niños/as que habitan en espacios de urbanización formal de nivel bajo, y casi 33 puntos entre los niños/as que residen en espacios formales de nivel medio.

Con respecto a la descomposición por nivel educativo de la madre, se observa que los niños/as cuya madre no ha terminado el secundario, registran mayor tendencia relativa de pobreza que aquellos cuyas madres han terminado el secundario e incluso han continuado sus estudios. En este sentido, los hijos/as de madres con bajos niveles educativos, registran 19 puntos 


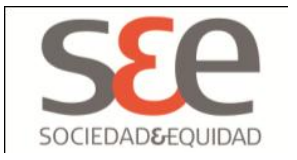

porcentuales más de posibilidades de experimentar una situación de pobreza por ingresos y por carencias sociales que aquellos con madres que han finalizado el secundario; 12,5 puntos porcentuales más de posibilidades de experimentar pobreza únicamente por ingresos, y 6,6 puntos únicamente debido a carencias sociales.

Al analizar la descomposición por condición laboral del jefe de hogar, se advierte que los niño/as cuyos jefes de hogar son desempleados/subempleados, registran mayores oportunidades relativas de ser pobres por ingresos y por carencias sociales, así como también de ser pobres únicamente por ingresos. Adicionalmente se observa que los niños/as en hogares cuyo jefe/a es inactivo o tiene un empleo precario, presentan más posibilidades de ser pobres únicamente debido a carencias sociales. En contraposición a ello, son los niño/as de hogares con jefe/a en empleo pleno quienes presentan menos posibilidades de experimentar situación de pobreza.

Los niño/as y adolescentes en hogares monoparentales tienen mayor probabilidad de ser pobres por ingresos y por carencias sociales, así como también de ser pobres únicamente por ingresos. Lo mismo se advierte a medida que aumenta la cantidad de niños/as en el hogar, como también en los hogares que reciben asistencia del Estado respecto de los que no la reciben.

Entonces podríamos aseverar que lo más específico de la doble pobreza infantil (en términos de dimensiones de derechos e ingresos familiares), es la residencia en espacios informales de villa o asentamiento urbano, y la mayor propensión al trabajo infantil. Esto pues la probabilidad de pertenecer a hogares bajo la línea de pobreza sin carencias sociales es mayor en el interior urbano, y en términos generales se advierte con mayor heterogeneidad en relación a varios de los factores analizados.

Comprobamos que la propensión a la pobreza multidimensional sin pobreza por ingresos presenta menor desigualdad en términos de la situación ocupacional del jefe/a de hogar y la cantidad de miembros niños/as que la observada en las otras poblaciones pobres. También que existe mayor propensión a dicha pobreza en la infancia del Conurbano Bonaerense, específicamente en el espacio de villa o asentamiento urbano, y al parecer especialmente en los hogares con progenitores jóvenes, y con niños/as pequeños. 


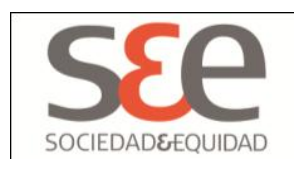

FIGURA IX. POBREZA INFANTIL MULTIDIMENSIONAL Y PERTENENCIA A HOGARES POBRES POR INGRESOS

En porcentaje de niños, niñas y adolescentes entre 0 y 17. Año 2011

\begin{tabular}{|c|c|c|c|}
\hline & $\begin{array}{c}\text { Pobres en hogares } \\
\text { no pobres por } \\
\text { ingresos }\end{array}$ & $\begin{array}{c}\text { No pobres en } \\
\text { hogares pobres } \\
\text { por ingresos }\end{array}$ & $\begin{array}{c}\text { Pobres en } \\
\text { hogares pobres } \\
\text { por ingresos }\end{array}$ \\
\hline TOTAL & 11,8 & 18,3 & 14,7 \\
\hline \multicolumn{4}{|l|}{ AGLOMERADOS URBANOS } \\
\hline$\overline{\mathrm{AMBA}}$ & 13,1 & 18,2 & 15,1 \\
\hline Ciudad Autónoma de Buenos Aires & 7,1 & 11,1 & 8,6 \\
\hline Conurbano Bonaerense & 14,5 & 19,7 & 16,5 \\
\hline Total Urbano Interior & 9,6 & 18,6 & 14,2 \\
\hline \multicolumn{4}{|l|}{ CONDICIÓN RESIDENCIAL } \\
\hline Urbanización informal & 25,8 & 24,2 & 36,3 \\
\hline Urbanización formal de nivel bajo & 11,6 & 22,7 & 17,5 \\
\hline Urbanización formal de nivel medio & 7,9 & 8,9 & 3,5 \\
\hline \multicolumn{4}{|l|}{ CLIMA EDUCATIVO DE LA MADRE } \\
\hline Hasta secundario incompleto & 14,3 & 24,6 & 23,6 \\
\hline Secundario completo y superior & 7,7 & 12,1 & 4,8 \\
\hline \multicolumn{4}{|l|}{ EDAD DE LA MADRE } \\
\hline Hasta 24 años & 17,9 & 22,4 & 15,8 \\
\hline 25 a 45 años & 10,6 & 18,3 & 14,3 \\
\hline 46 y más & 9,7 & 17,1 & 15,7 \\
\hline \multicolumn{4}{|l|}{ OCUPACIÓN DEL JEFE } \\
\hline Inactivo & 14,7 & 26,3 & 15,4 \\
\hline Desempleado-subempleado & 10,5 & 34,5 & 33,0 \\
\hline Precario & 14,3 & 20,2 & 20,1 \\
\hline Pleno & 10,2 & 12,7 & 7,9 \\
\hline \multicolumn{4}{|l|}{ TIPO DE HOGAR } \\
\hline Resto & 11,4 & 17,9 & 14,1 \\
\hline Monopaternal & 13,8 & 20,5 & 17,6 \\
\hline \multicolumn{4}{|l|}{ CANTIDAD DE NIÑOS EN EL HOGAR } \\
\hline 1 a 2 & 12,9 & 10,9 & 7,3 \\
\hline 3 a 4 & 11,5 & 23,2 & 40,9 \\
\hline 5 o más & 7,3 & 40,9 & 41,0 \\
\hline \multicolumn{4}{|l|}{ ASISTENCIA SOCIAL } \\
\hline $\begin{array}{l}\text { Salario familiar/Autónomos/Asalariados con } \\
\text { ingresos superiores a } \$ 5200\end{array}$ & 11,0 & 8,4 & 6,1 \\
\hline $\begin{array}{l}\text { Asignación Universal por } \mathrm{Hijo}(\mathrm{AUH}) / \text { otros } \\
\text { planes sociales }\end{array}$ & 14,3 & 27,4 & 26,6 \\
\hline Sin asistencia & 9,0 & 24,9 & 13,4 \\
\hline \multicolumn{4}{|l|}{ SEXO DE LOS NIÑOS EN EL HOGAR } \\
\hline Varón & 12,9 & 18,1 & 14,2 \\
\hline Mujer & 10,6 & 18,5 & 15,3 \\
\hline \multicolumn{4}{|l|}{ GRUPO DE EDAD } \\
\hline 0 a 4 años & 15,4 & 16,0 & 14,2 \\
\hline 5 a 12 años & 9,5 & 19,6 & 12,7 \\
\hline 13 a 17 años & 12,1 & 18,5 & 18,4 \\
\hline \multicolumn{4}{|c|}{ TRABAJO INFANTIL: ECONÓMICO Y DOMÉSTICO } \\
\hline No trabaja & 11,4 & 18,2 & 12,5 \\
\hline Trabaja & 14,4 & 19,3 & 29,5 \\
\hline
\end{tabular}

Fuente: Elaboración propia con base en datos de la EDSA-Bicentenario (2010-2016). Año 2011. Obervatorio de la Deuda Social Argentina (ODSA- UCA) 


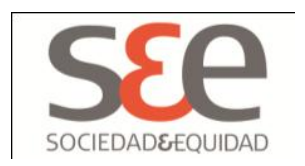

\section{Reflexiones finales}

En este artículo se presentaron algunos de los avances sobre la definición de la pobreza infantil en Argentina urbana, así como ejercicios de estimación de la misma.

Se considera importante lograr más y mejores aproximaciones a la definición de la pobreza en la niñez y adolescencia desde perspectivas alternativas y complementarias a las medidas indirectas, que sean pensadas desde un enfoque de derechos. En este sentido, parece relevante acompañar los progresos de los Estados y en particular del Estado y la sociedad argentina en el reconocimiento de la infancia como sujeto de derecho.

En la primera década del s.XXI, se destaca la ampliación de derechos y la implementación de políticas públicas de transferencia de ingresos hacia los sectores sociales más vulnerables y en particular hacia las infancias (Tuñón, 2011; 2012).

Todos los esfuerzos que se desarrollen en pos de alcanzar mejores definiciones y estimaciones de la pobreza en la infancia parecen insumos valiosos para la planificación de políticas públicas destinadas a estas poblaciones. No sólo son insumos importantes para una mejor definición de las privaciones en la niñez y adolescencia, para la identificación de áreas o dimensiones de derechos más vulneradas, y la identificación de poblaciones más vulnerables en el interior de la pobreza; sino también como recurso desde el cual instalar en la agenda pública las particularidades de la experiencia de la pobreza infantil y su impronta en la reproducción intergeneracional.

El enfoque de derechos es valioso pues establece umbrales con amplio consenso en las sociedades, cuya garantía puede ser legítimamente exigida a los Estados. Los abordajes multidimensionales de la pobreza permiten advertir sobre la complejidad de la misma y los múltiples factores asociados a las estrategias de cuidado, crianza, socialización e inclusión educativa. Permite poner en evidencia entonces los límites que presentan los programas sociales que basan su criterio de elegibilidad de las poblaciones únicamente a partir de indicadores de pobreza económica. Las estimaciones y análisis de la pobreza infantil en esta doble perspectiva, de derechos y multidimensional, puede aportar a la construcción de estructuras de oportunidades más integrales.

La reciente propuesta de CEPAL y UNICEF para la medición de la pobreza en la infancia, ha sido muy significativa en términos de su concepción teórica, y abona avances importantes, como los desarrollados por CONEVAL en México. Por ello, se valoró realizar una propuesta de adaptación y estimación para el caso de la infancia urbana en la Argentina. En esta comunicación hemos avanzado en su definición operativa, construida a partir de los indicadores de la EDSA, calculando y analizando su incidencia en la población de niños, niñas y adolescentes de las grandes ciudades de la argentina. 


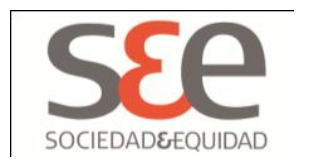

Aún queda pendiente avanzar sobre otras dimensiones de derechos que adquieren especial relevancia en la niñez y adolescencia, como aquellos aspectos asociados a las "protecciones especiales". Dentro de esta dimensión de derechos, el lograr consensos sobre los indicadores de bienestar emocional, sería un interesante aporte para la definición de la pobreza infantil de Unicef (2005). Creemos relevante avanzar sobre indicadores que permitan aproximarse a los procesos de crianza y estimulación en los primeros años de vida, cuando la inclusión educativa no es obligatoria, pero las oportunidades de estimulación emocional, sensorial e intelectual, son fundamentales para el desarrollo neuronal (Bronson, 2000). Tomando en cuenta que la principal fuente de estrés para el niño/a es la insatisfacción de sus necesidades, y que éstas son muchas veces vulneradas en situación de pobreza económica, pero también por negligencia en el cuidado, abandono y maltrato, creemos que debieran considerarse indicadores del déficit de estimulación en los primeros años de vida y de maltrato infantil y adolescente.

En este proceso de reflexión hemos advertido los límites de algunos de los indicadores en términos del ejercicio de derechos: uno de ellos es que en países como Argentina la inclusión educativa no parece un indicador suficiente para evaluar el derecho a la educación. Lo anterior, puesto que existe un amplio conocimiento construido sobre los procesos de segmentación educativa en Argentina, esto es: las disímiles ofertas educacionales que presentan las escuelas públicas en cuanto a calidad, y su fuerte correlato con la situación socioeconómica y socioresidencial de los hogares de los niños que en ellas se educan. En esta misma línea de análisis cabe ubicar el derecho a la salud.

Sin dudas son muchos los dilemas en torno a cuáles son los indicadores que mejor nos aproximan a la medición de los déficit de desarrollo humano de la niñez y adolescencia en perspectiva de derechos. Alcanzar consensos en torno a cuáles son las condiciones de cumplimiento de los derechos, y en especial en la niñez y adolescencia, parece un desafío prioritario que debiera comprometer a los Estados, y al conjunto de las sociedades.

Consciente de estas tensiones, avanzamos sobre la revisión de la propuesta de medición de la pobreza infantil de CEPAL y UNICEF (2012), y su estimación para el caso de la infancia y adolescencia en Argentina urbana. Los desafíos son interesantes y las posibilidades muchas, la EDSA resulta un insumo clave pero también limitado para la identificación desagregada a nivel territorial, aun cuando la consideramos un aporte fundamental para la construcción de políticas públicas.

Esta primera aproximación que hemos realizado, nos permite reconocer que tras casi una década de importantes progresos sociales y económicos, llegamos al segundo año del período del Bicentenario con una incidencia de la pobreza multidimensional que afecta al $26,6 \%$ de la niñez y adolescencia urbana argentina. La experiencia de la pobreza infantil en la Argentina se reparte en aspectos severos y moderados de forma bien similar. En cualquier 


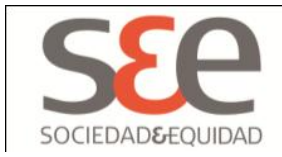

caso, al menos dos de cada diez niños/as y adolescentes ven vulnerados al menos un derecho básico para el sostenimiento de su vida y su desarrollo tanto humano como social.

No es menor el dato que señala que el $15 \%$ de la niñez pertenece a hogares pobres en términos de ingresos y en términos de derechos, y que el 2,3\% son extremadamente pobres en términos de derechos e indigentes por ingresos. Esta es una importante aproximación a la estimación de un núcleo duro de la pobreza infantil, que los progresos económicos y la ampliación de derechos no han logrado revertir.

Las dimensiones de derechos más afectadas en la niñez y adolescencia son el espacio del hábitat de vida, es decir, el derecho a la vivienda digna, y a condiciones de saneamiento adecuadas. Dos aspectos centrales al sostenimiento de la vida por su fuerte impronta sobre la salud de los niños/as, pero también sobre aspectos fundamentales del desarrollo humano como son los logros educativos. La deuda social con el espacio habitacional de la infancia explica el $66 \%$ de la pobreza severa.

En el interior de esta población vulnerada en sus derechos esenciales, se advierten situaciones de mayor severidad, como lo es residir en un espacio social de villa o asentamiento urbano, en hogares de muy bajo clima educativo, y en hogares jóvenes en términos de la edad de los progenitores, donde las inserciones socio ocupacionales son muy precarias y suelen incluir el trabajo infantil. El trabajo infantil se presenta cuando aumenta la cantidad de niños/as en el hogar, o cuando los hogares no cuentan con ingresos suficientes y/o son beneficiarios de programas sociales. Todos estos aspectos están fuertemente asociados a la propensión a la pobreza. Por lo tanto, su identificación resulta necesaria para la mejor definición de los problemas sociales y las deudas pendientes, lo que permitirá la construcción de políticas públicas más integrales.

\section{Referencias Bibliografía}

Adazko, D. y González, M. S. (2010). La distribución del Ingreso per cápita del hogar, en Salvia, A. La Deuda Social Argentina frente al bicentenario. Progresos Destacados y Desigualdades Estructurales del Desarrollo Humano y Social en la Argentina Urbana 2004-2009. Observatorio de la Deuda Social Argentina, Departamento de Investigación Institucional: Editorial EDUCA. ISSN 1852-4052.

Alkire, S. (2002). Valuing Freedoms. Oxford: Oxford University Press. 


\section{SEe}

Foster, J., Greer, J. y Thorbecke E. (1984). A class of decomposable poverty measures. Econométrica, vol. 52, № 3, mayo.

Alkire, S. y Foster, J. (2007). Counting and multidimensional poverty measurement, Working Paper $\mathrm{N}^{\circ} 7$ and No 32 (revised), Oxford Poverty and Human Development Initiative.

Boltvinik, J. (2003). Eje de florecimiento humano y medición de la pobreza. Papeles de Población, México DF: Centro de Investigación y Estudios Avanzados de la población.

Bolzán, A. y Mercer, R. (2009). Seguridad alimentaria y retardo crónico del crecimiento en niños pobres del norte argentino. Arch Argent Pediatr vol. $107 \mathrm{~N}$ 3 pp. 221-228. Disponible desde Internet en: http://www.sap.org.ar/docs/publicaciones/archivosarg/2009/v107n3a06.pdf.

Bronson, M. B. (2000). La autorregulación en la primera infancia: naturaleza y la crianza, Nueva York: Guilford Press.

Bourguignon, F. y Chakravarty, S. (2003). The measurement of multidimensional poverty. Journal of Economic Inequality, vol. 1, No 1, Abril.

CDESC (2001). Cuestiones sustantivas que se plantean en la aplicación del Pacto Internacional de Derechos Económicos, Sociales y Culturales: la Pobreza y el Pacto Internacional de Derechos Económicos, Sociales y Culturales. Ginebra: ONU.

CELS (2009). El CELS reclamó al INDEC que publique datos para analizar políticas sociales. Disponible desde Internet en: http: / / www.cels.org.ar/documentos/?info=detalleDoc\&ids=3\&lang=es\&ss=\&idc $=1119$.

CEPAL y UNICEF (2012). Guía para estimar la pobreza infantil. LC/M.2 Santiago de Chile, Abril.

Cerrutti, M. y Binstock, G. (Septiembre, 2004). Camino a la exclusión: determinantes del abandono escolar en el nivel medio en la Argentina. Trabajo presentado en el I Congreso ALAP (Asociación Latinoamericana de Población), Casambu, Brasil. Disponible desde Internet en: http://www.abep.nepo.unicamp.br/site_eventos_alap/PDF/alap2004_291.PDF.

CONEVAL (2010). Metodología para la medición multidimensional de la pobreza en México. México. 


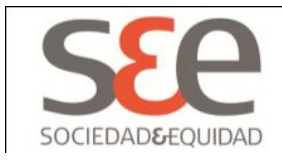

Constitución Nacional de la República Argentina. Disponible desde Internet en: ww.senado.gov.ar/web/interes/constitucion/cuerpo1.php

Convención Interamericana de Derechos Humanos (Pacto San José de Costa Rica). Disponible desde Internet en: www.oas.org/juridico/spanish/tratados/b32.html.

Doyal, L. y Gough, I. (1994). Teoría de las Necesidades humanas, Barcelona: Fontanella.

DWP (2003). Measuring Child Poverty. Londres. Disponible desde Internet en: www.dwp.gov.uk/docs/final-conclusions.pdf .

Herrán, C.A. y B. Van Uythem (2001). ¿Por qué los jóvenes en Argentina desertan de la escuela y qué puede hacerse para combatir este problema? Diálogo regional de política. BID, Segunda Reunión, Julio 19 y 20.

Ley 26.061 de Protección Integral de los derechos de los niños, niñas y adolescentes Disponible desde Internet en: www.infoleg.gov.ar.

Ley 26.206 Ley Nacional de Educación. Disponible desde Internet en: www.infoleg.gov.ar.

López, N. (2001). La articulación de las familias con el mercado de trabajo y su impacto sobre los adolescentes. Serie Documentos de Trabajo, No 5, SIEMPRO. Octubre.

Max-Neef, M. (1987). Desarrollo a escala humana, Montevideo: Nordan.

Minujín, A., Delamónica, E. y Davidziuk (2006). Pobreza infantil. Conceptos, medición y recomendaciones de políticas públicas, Cuaderno de Ciencias Sociales, $\mathrm{N}^{\circ}$ 140, Costa Rica: Facultad Latinoamericana de Ciencias Sociales (FLACSO).

Niccolini, C. y Cárcova, M. (2009). El Derecho a la Salud. La vigencia de los derechos humanos en la Ciudad Autónoma de Buenos Aires a la luz del Derecho Supranacional, en Colección Diagnósticos. Elaboración: Área de Salud e Integración Social de la Defensoría del Pueblo de la Ciudad Autónoma de Buenos Aires.

Nussbaum, M. y Glover, J. (1995). Women, Culture and Development: a study of human capabilities, Oxford: Clarendon. 


\section{sfe \\ SOCIEDADEEQUIDAD}

O’ Donnell, G. (2002). Human Development / Democracy / Human

Rights. Ponencia presentada en Calidad de la Democracia y Desarrollo Humano en América Latina, Costa Rica. Disponible desde Internet en: www.estadonacion.org.cr.

OMS. (2006). Meeting the mdg drinking water and sanitation target. The urban and rural challenge of the decade. Ginebra.

OMS, UNICEF. (2000). Evaluación Mundial del Abastecimiento de Agua y Saneamiento en 2000. Ginebra.

ONU. (1989). Convención sobre los Derechos del Niño. Disponible desde Internet en: http://www.unicef.org/spanish/crc/.

ONU. (2004). Human Rights and Poverty Reduction. A Conceptual Framework. Nueva York-Ginebra: ONU.

PNUD. (2000). Human Development Report. Human Rights and Human Developmen, New York.

Salvia, A.; Tuñon, I. y Musante, B. (2012). Informe sobre la Inseguridad Alimentaria en la Argentina. Hogares Urbanos. Año 2011. Documento de trabajo del Observatorio de la Deuda Social Argentina. Buenos Aires: Observatorio de la Deuda Social/UCA.

Sen, A. (1976). Poverty: An Ordinal Approach to Measurement. Econométrica, 44(2), pp. 219-231.

Sancevich, V. (2006). Diagnóstico: Gestión de Salud Pública. Trabajo presentado en II Parlamento Universitario Latinoamericano. Programa de Evangelización de la Cultura: Universidad Católica Argentina.

Tuñón, I. y González, M.S. (Octubre, 2012). Factores macroeconómicos y sociodemográficos asociados a la pobreza infantil desde una perspectiva de derechos. Trabajo presentado en V Congreso ALAP (Asociación Latinoamericana de Población), Montevideo, Uruguay.

Tuñón, I. (2010). Determinantes de las oportunidades de crianza y socialización en la niñez y adolescencia, en: Revista Latinoamericana de Ciencias Sociales, Niñez y Juventud, vol. $8, \mathrm{n}^{\circ} 2$. Artículo con referato académico. 


\section{SEe}

Tuñón, I. (2011). Situación de la Infancia a inicios del Bicentenario. Un enfoque multidimensional y de derechos. Barómetro de la Deuda Social de la Infancia, Observatorio de la Deuda Social Argentina: Fundación UCA.

Tuñón, I. (2012). La infancia Argentina sujeto de derecho. Progresos, desigualdades y desafíos en el efectivo cumplimiento de los derechos de niños, niñas y adolescentes. Barómetro de la Deuda Social de la Infancia, Observatorio de la Deuda Social Argentina: Fundación UCA.

UNICEF (2005). Manual para la encuesta de indicadores múltiples por conglomerados. Dar seguimiento a la Situación de Niños, niñas y mujeres. División de políticas y planificación: MICS.

UNICEF (2009). Estado Mundial de la Infancia. Conmemoración de los 20 años de la Convención sobre los Derechos del Niño. 